\title{
Oncologic Effectiveness and Safety of Splenectomy in Total Gastrectomy for Proximal Gastric Carcinoma: Meta-analysis of Randomized Controlled Trials
}

\author{
LUIGI MARANO ${ }^{1}$, FABIO RONDELLI $^{2,3}$, ALBERTO BARTOLI ${ }^{1}$, MARIO TESTINI ${ }^{4}$, \\ GIAMPAOLO CASTAGNOLI ${ }^{1}$ and GRAZIANO CECCARELLI ${ }^{3}$ \\ ${ }^{1}$ General, Minimally Invasive and Robotic Surgery, Department of Surgery, \\ San Matteo degli Infermi Hospital- AUSL Umbria 2, Spoleto, Italy; \\ ${ }^{2}$ General and Oncologic Surgery, Department of Surgical and Biomedical Sciences, \\ University of Perugia, Perugia, Italy; \\ ${ }^{3}$ General Surgery, Department of Surgery, San Giovanni Battista Hospital-AUSL Umbria 2, Foligno, Italy; \\ ${ }^{4}$ Department of Biomedical Sciences and Human Oncology, Unit of Endocrine, \\ Digestive and Emergency Surgery, A. Moro University Medical School of Bari, Bari, Italy
}

\begin{abstract}
Background/Aim: The role of splenectomy as an essential component of radical surgery for proximal gastric cancer, from an oncological point of view, is still debated, and no consistent recommendations have been proposed. The aim of this systematic review with meta-analysis was to provide a more robust answer regarding the oncological effectiveness and safety of splenectomy in total gastrectomy for proximal gastric carcinoma. Materials and Methods: A systematic review and meta-analysis of randomized controlled trials was planned and performed in accordance with Preferred Reporting Items for Systematic Review and Meta-analysis (PRISMA) statement and Cochrane Handbook for Systematic Reviews of Intervention. Patients with a histological diagnosis of gastric adenocarcinoma located in the upper third of the stomach who underwent D2 total gastrectomy with or without splenectomy were selected. The primary outcome was to analyze the influence of splenectomy on the overall survival of patients. Additionally, the mean difference in procedure time, length of hospital stay, number of retrieved lymph nodes, as well as the odds ratio of postoperative complications comparing splenectomy to spleen preservation were investigated in a secondary analysis Results: Overall, four studies with a total of 978 patients met the inclusion criteria.
\end{abstract}

Correspondence to: Luigi Marano, MD, Ph.D., General, Minimally Invasive and Robotic Surgery, Department of Surgery, San Matteo degli Infermi Hospital - ASL Umbria 2, Via Loreto 3, 06049, Spoleto (PG), Italy. Tel: +39 3923520589, e-mail: marano.luigi@email.it

Key Words: Gastric cancer, splenectomy, spleen-preservation, metaanalysis, total gastrectomy.
The pooled analysis showed no difference in overall survival rates between those who underwent spleen preservation compared to the splenectomy-treated group (risk ratio $=0.92$, $95 \%$ confidence interval $=0.79$ to $1.06, p=0.277$ ). Interestingly, all studies reporting overall morbidity data highlighted statistically significant differences in favor of spleenpreservation group (odds ratio=2.11, 95\% confidence interval $=1.44$ to $3.09, p<0.001)$. Conclusion: In total, gastrectomy for proximal gastric cancer, splenectomy should not be recommended as it increases operative morbidity without improving survival when compared to spleen preservation. Furthermore, our results may help in planning the updated versions of Gastric Cancer Treatment Guidelines. This meta-analysis, however, points to the urgent need for high-quality, well-designed, large-scale, clinical trials, with short-as well as long-term evaluation comparing splenectomy with spleen-preserving procedures, in a controlled randomized manner to help future research and to establish an evidencebased approach to gastric cancer treatment.

Gastric cancer, despite decreasing in incidence in recent decades, is still the third leading cause of cancer-related death around the world (1). Interestingly, researchers are facing clinically relevant changes in epidemiological trends according to the location and histotype of gastric cancer: while the overall number of newly diagnosed gastric cancer cases is decreasing, with tumors located in the distal third of the stomach showing the most evident decrease, the incidence of proximal tumors has remained stable or even increased over time (2-5). Similarly, a relative increase in Lauren diffuse histotype tumors has also been registered (57). As a result, since the proximal location as well as the 
diffuse histotype are associated with higher biological and clinical aggressiveness and worse prognosis, emerging epidemiological trends could lead to a general decrease in overall survival (8-11). Currently, surgical R0 resection with D2 lymph node dissection represents the only curative treatment for non-metastatic proximal gastric cancer (12), while neoadjuvant and adjuvant chemotherapies, as well as chemoradiation, improve outcomes, aiming at reduction of recurrence and extension of survival (13). To this aim, for tumors directly invading the spleen, splenectomy should be considered as a part of standard D2 total gastrectomy (14). In the absence of direct invasion, on the other hand, splenectomy is also performed to ensure complete resection of nodal stations 10 and 11 in surgically challenging and technically demanding cases. Nevertheless, the role of splenectomy as an essential component of radical surgery for proximal gastric cancer, from an oncological point of view, is still debated (12). No consistent recommendations have been proposed since the available data are ambiguous, with some studies reporting slightly, but not significantly better survival with splenectomy (15-17), while conflicting results are reported from other studies (18-20). However, despite all these inconclusive results, the splenectomy rate continues to be high, ranging from 26-48.7\% (21-24).

We therefore undertook a systematic review and metaanalysis of currently available data in order to provide a more robust answer regarding the oncological effectiveness and safety of splenectomy in total gastrectomy for proximal gastric carcinoma.

\section{Materials and Methods}

Literature search. This systematic review with meta-analysis was performed in accordance with the Preferred Reporting Items for Systematic Review and Meta-analysis (PRISMA) statement (25) and the Cochrane Handbook for Systematic Reviews of Interventions (26). A literature search was undertaken in PubMed, Cochrane, Embase and Ovid databases for all articles published up to December 2017 with the follow Medical Subject Headings $(\mathrm{MeSH})$ and key word search: ("gastric cancer" OR "gastric carcinoma" OR "gastric adenocarcinoma" OR "stomach neoplasm" OR "stomach cancer" OR "stomach carcinoma") AND ("splenectomy" OR "spleen resection") AND ("spleen preserving" OR "spleen preservation" OR "splenic preservation") AND (Publication Type:"comparative study" OR "follow-up studies" OR "clinical trial" OR "evaluation studies" OR "randomized controlled trial" OR "controlled clinical trial" OR "research design"). The search was carried out independently by two investigators. The key words were used in all possible combinations to obtain the maximum number of articles. We also reviewed the bibliographies of relevant articles to identify additional publications.

Article selection. The articles were screened for the presence of the following defined eligibility criteria according to the PICO (population, intervention, comparator, outcome) format (27). PPopulation: Patients with a histologically diagnosis of gastric adenocarcinoma located in the upper third of the stomach who underwent surgical treatment without previous chemotherapy or surgery for gastric cancer. I-Intervention: D2 total gastrectomy with splenectomy; C-Comparator: D2 total spleen-preserving gastrectomy; O-Outcomes of interest: prognostic characteristics and postoperative outcomes. Only randomized controlled trials (RCTs) with full text were included. Experimental studies in animal models, single case reports, technical reports, reviews, abstracts and editorials were excluded. When the same population was included in multiple publications, only data from the most recent article were used for meta-analysis.

Data extraction. Two of the Authors (L.M. and F.R.) independently reviewed the formal published versions of all eligible studies for content according to the specified inclusion criteria using a data extraction form based on the Cochrane Consumers and Communication Review Group's data extraction template (26). Disagreements were resolved by discussion or consultation with third Author.

Data recorded included: first author, study design, study setting (single-center or multicenter), country of origin, year of publication, study period, sample size, demographic features, clinicopathological characteristics, operative factors, intra-and postoperative complications, total number of patients assessed in survival analysis, median or mean duration of follow-up, control and intervention groups for estimation of hazard ratio (HR), and overall survival outcomes. Authors of articles were contacted for more detailed data when necessary.

This study did not require ethical approval and informed consent since all analyses were based on the previous published data.

Summary outcome measures. The primary outcome was to analyze the influence of splenectomy on the overall survival of patients with proximal gastric cancer by comparing the prognosis of patients undergoing gastrectomy with splenectomy for proximal gastric cancer with that of patients undergoing spleen-preserving gastrectomy. Additionally, the mean difference in procedure time, length of hospital stay, number of retrieved lymph nodes, as well as the odds ratio of postoperative complications comparing splenectomy to spleen preservation were investigated as a secondary analysis.

Quality assessment. All eligible articles were evaluated independently by two reviewers for risk of bias according to the Quality In Prognosis Study (QUIPS) tool (28). Risk of bias was scored as low, moderate or high for each domain, based on answers to three to six questions for six items: study participation, study attrition, prognostic factor measurement, outcome measurement, study confounding and statistical analysis. A final grading of low risk of bias was assigned when three or more of the six items were considered to be of high methodological quality;risk of bias was considered high when three or more of the six items were deemed to be of low methodological quality. Otherwise a moderate risk of bias was assigned.

Statistical analysis. Comprehensive Meta-Analysis software version 3.3.070 (Biostat, Englewood, NJ, USA) was used for metaanalysis. In pooled analyses of associations between various demographic and clinicopathological variables and splenectomy/non-splenectomy, effect sizes were calculated as odds ratios (ORs) with $95 \%$ confidence intervals. The HR and $95 \%$ confidence interval for overall survival were retrieved from each article where possible; otherwise the value was estimated according 


\section{PRISMA 2009 Flow Diagram}
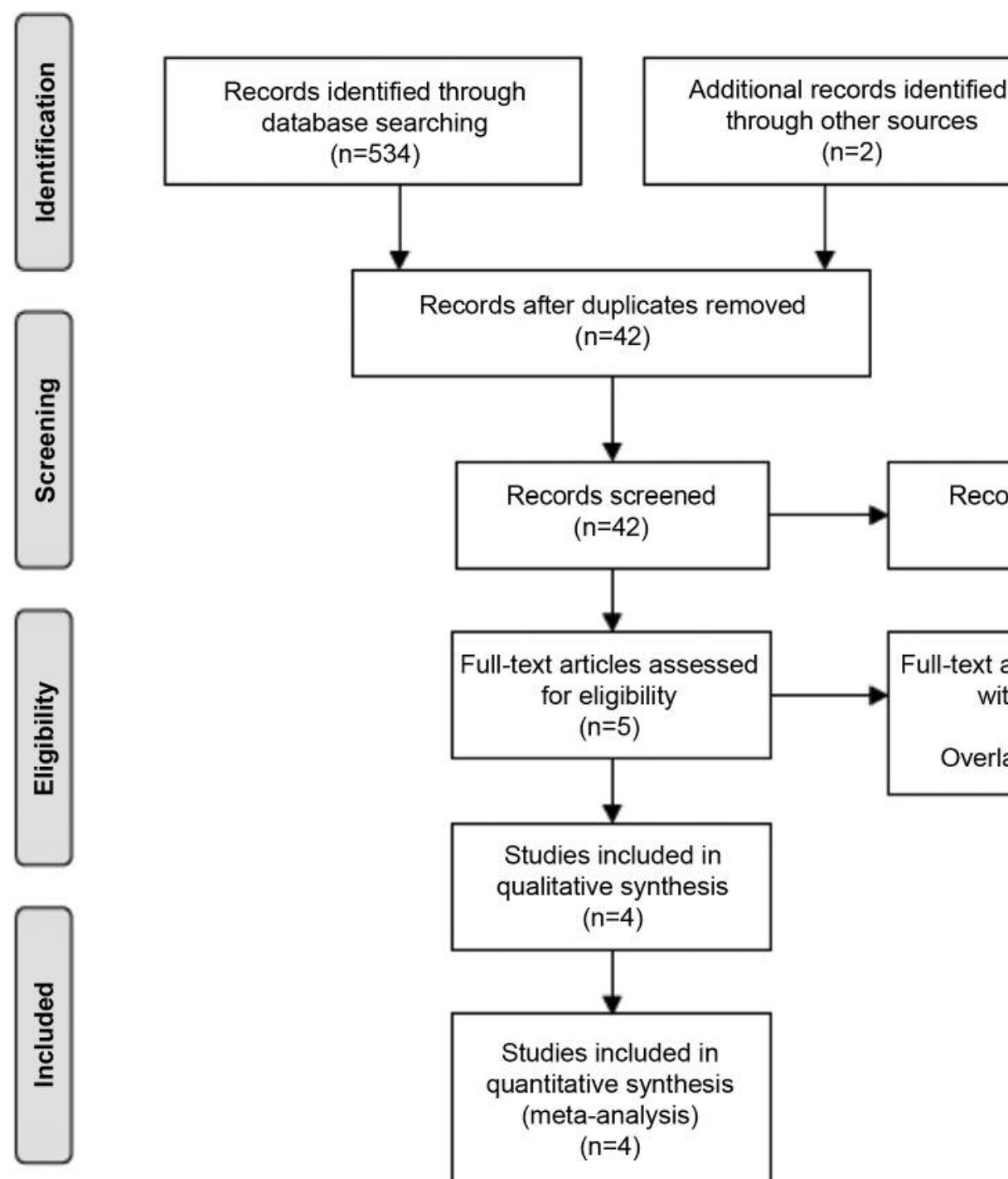

Figure 1. Preferred Reporting Items for Systematic Review and Meta-analysis (PRISMA) flow chart of study selection.

to the method of Tierney and colleagues (29) using Plot Digitizer version 2.5.1 (http://plotdigitizer.sourceforge.net/). The pooled HR was estimated in meta-analysis. Between-study heterogeneity was explored using the Higgins $I^{2}$ measure (26). $I^{2}$ values of around $25 \%, 50 \%$ and $75 \%$ were considered to represent low, moderate and high heterogeneity respectively. When the $I^{2}$ value exceeded $50 \%$, the effect size for each study was calculated by a randomeffects model using the DerSimonian and Laird approach (26); otherwise, a fixed-effect model was used. A chi-squared-based
Q-test was also performed to check between-study heterogeneity, with values of $p<0.100$ considered statistically significant. Potential sources of heterogeneity were investigated in subgroup analyses.

Funnel plots to test the publication bias were not performed due to the limited number of studies (fewer than 10) included in each analysis (25). This study did not require ethical approval or informed consent due to analyses being carried out based on the previous published data. 
Table I. Characteristics of the included studies.

\begin{tabular}{|c|c|c|c|c|c|c|c|c|c|c|}
\hline \multirow[b]{2}{*}{ Author } & \multirow[b]{2}{*}{$\begin{array}{l}\text { Study } \\
\text { period }\end{array}$} & \multirow[b]{2}{*}{$\begin{array}{c}\text { Country of } \\
\text { origin }\end{array}$} & \multicolumn{2}{|c|}{ Sample size, $n(M / F)$} & \multicolumn{2}{|c|}{ Age, years ${ }^{\mathrm{a}}$} & \multicolumn{2}{|c|}{$\mathrm{pT} 1 / \mathrm{T} 2 / \mathrm{T} 3 / \mathrm{T} 4, \mathrm{n}$} & \multirow[b]{2}{*}{$\begin{array}{l}\text { OS, HR } \\
(95 \% \text { CI })\end{array}$} & \multirow[b]{2}{*}{ Follow-up } \\
\hline & & & Splenectomy & $\begin{array}{c}\text { Spleen } \\
\text { preservation }\end{array}$ & Splenectomy & $\begin{array}{c}\text { Spleen } \\
\text { preservation }\end{array}$ & Splenectomy & $\begin{array}{c}\text { Spleen } \\
\text { preservation }\end{array}$ & & \\
\hline Sano et al. (18) & $\begin{array}{l}2002- \\
2009\end{array}$ & Japan & $254(196 / 58)$ & $251(204 / 47)$ & $65(27-75)$ & $65(30-75)$ & $31 / 144 / 78 / 1$ & $40 / 155 / 55 / 1$ & $\begin{array}{c}0.86 \\
(0.62-1.18)\end{array}$ & 71.8 \\
\hline Yu et al. (16) & $\begin{array}{l}1995- \\
1999\end{array}$ & Korea & $104(72 / 32)$ & $103(72 / 31)$ & $57(24-78)$ & $57(31-78)$ & $10 / 56 / 35 / 3$ & $9 / 49 / 43 / 2$ & $\begin{array}{c}1.13 \\
(0.87-1.47)\end{array}$ & 64.8 \\
\hline Csendes et al. (15) & $\begin{array}{l}1985- \\
1992\end{array}$ & Chile & 90 (NR) & 97 (NR) & & $62(29-80)$ & NR & NR & $\begin{array}{c}1.16 \\
(0.80-1.67)\end{array}$ & $\begin{array}{c}\text { At least } \\
5 \text { years }\end{array}$ \\
\hline Toge et al. (17) & NR & Japan & 41 (NR) & 38 (NR) & NR & NR & NR & NR & $\begin{array}{c}1.28 \\
(0.90-1.81)\end{array}$ & $\begin{array}{c}\text { At least } \\
5 \text { years }\end{array}$ \\
\hline
\end{tabular}

F: Female; M: male; OS: overall survival; NR: not reported; HR: hazard ratio; CI: confidence interval. aMedian (range).

Table II. Results of meta-analysis of the secondary outcomes.

\begin{tabular}{|c|c|c|c|c|c|c|}
\hline \multirow[t]{2}{*}{ Outcomes } & \multirow[t]{2}{*}{ Effect size } & \multirow[t]{2}{*}{$95 \% \mathrm{CI}$} & \multirow[t]{2}{*}{$p$-Value } & \multicolumn{2}{|c|}{ Heterogeneity } & \multirow[t]{2}{*}{ Effect model } \\
\hline & & & & $\mathrm{I}^{2}(\%)$ & $p$-Value & \\
\hline Operative time (minutes) & MD: 0.13 & $-0.01-0.28$ & 0.079 & 10.5 & 0.29 & Fixed \\
\hline Hospital stay (days) & MD: 0.06 & $-0.36-0.48$ & 0.783 & 77.8 & 0.034 & Random \\
\hline Retrieved lymph nodes (number) & MD: 0.18 & $0.03-0.32$ & 0.019 & 58.8 & 0.119 & Fixed \\
\hline No. 10 lymph node station & OR: 1.56 & $0.75-3.27$ & 0.232 & 22.2 & 0.257 & Fixed \\
\hline No. 11 lymph node station & OR: 1.21 & $0.47-3.12$ & 0.690 & 59.9 & 0.114 & Random \\
\hline Mortality & OR: 1.06 & $0.29-3.86$ & 0.925 & 0 & $<0.001$ & Fixed \\
\hline Postoperative complications & OR: 2.11 & $1.44-3.09$ & $<0.001$ & 0 & 0.79 & Fixed \\
\hline SSIs & OR: 1.44 & $0.72-2.88$ & 0.302 & 0 & 0.489 & Fixed \\
\hline Intraperitoneal infection & OR: 2.10 & $1.15-3.83$ & 0.016 & 0 & 0.731 & Fixed \\
\hline Pulmonary complications & OR: 1.68 & 0.94-2.99 & 0.292 & 25.4 & 0.247 & Fixed \\
\hline
\end{tabular}

MD, Mean difference; OR, odds ratio; CI, confidence interval; SSIs, surgical site infections.

\section{Results}

Study selection and characteristics. The initial search produced 534 studies, of which 492 were excluded because of duplication. After checking the relevant bibliography, two additional articles were included. The titles and abstracts of the remaining 42 records were screened and five studies fulfilled criteria for eligibility (Figure 1). Thirty-seven studies that were not related to the comparison between splenectomy and spleenpreserving total gastrectomy for proximal gastric cancer, or that were reviews, non-RCTs, editorial or case reports were excluded. Of the remaining five records, those by Sano et al. were included as one study, since they separately published complementary data from the same group of patients $(18,30)$.

After this screening, 4 RCTs published between 1985 and 2017 were included (15-18). The total number of included patients was 978 (489 in the splenectomy-treated group and
489 in the group with spleen preservation) ranging from 79 to 505 patients per study.

Only one study (505 patients, $51.6 \%$ ) was multicentric (36 institutions belonging to the Stomach Cancer Study Group of the Japanese Clinical Oncology Group, Japan) (31), while the others were performed at single centers in Eastern populations (286 patients, 29.2\%) from Japan (17) and South Korea (16), or in Western populations (187 patients, 19.2\%) from Chile (15). The overall proportion of patients who had undergone splenectomy was 50\% (489 patients), ranging from $48.1 \%$ (15) to $51.9 \%$ (17) patients per study. The main characteristics of each study included in the meta-analysis are shown in Table I. Since not all studies reported all variables examined in the meta-analysis, only studies reporting the variable of interest were included for quantitative synthesis to investigate the association of splenectomy with that variable. 


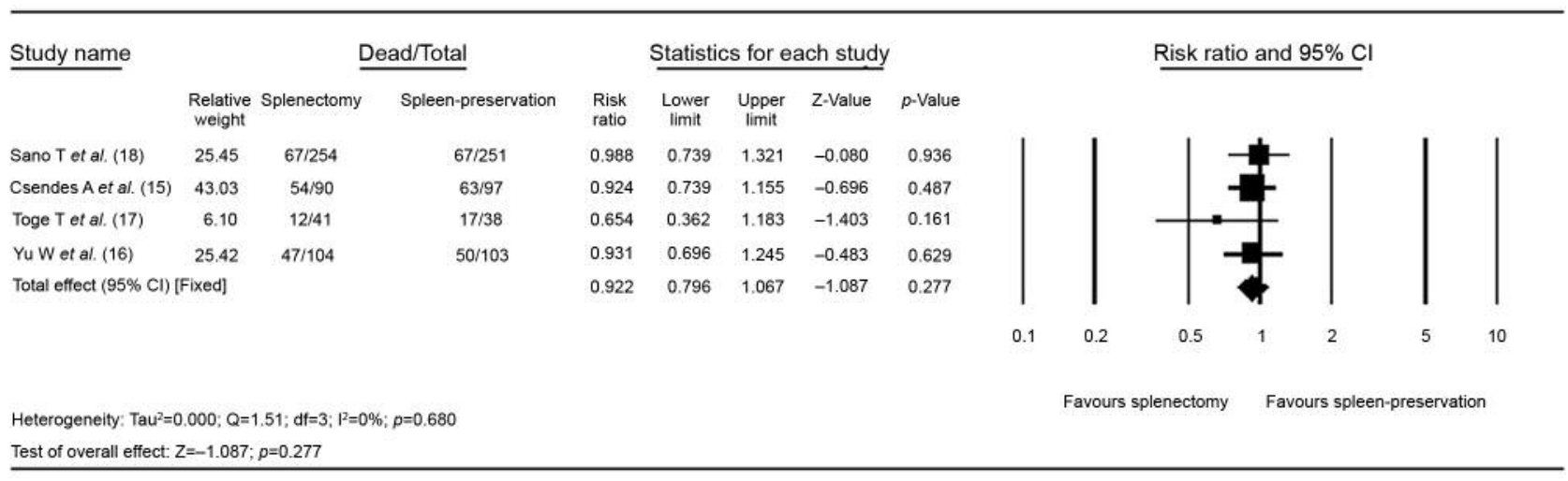

Figure 2. Forest plot of risk ratio with $95 \%$ confidence interval (CI) for the effect of splenectomy on overall survival (OS).

Splenectomy and survival of patients with gastric cancer. The range of follow-up was 64.8 to 71.8 months;two studies did not clearly specify the duration of follow-up for survival, reporting a period of at least 5 years $(15,17)$. All the selected studies found no statistically significant prognostic difference in terms of overall survival between the splenectomy versus spleen-preservation groups.

The pooled analysis showed no difference in the overall survival rate between the two groups (risk ratio $=0.92,95 \%$ $\mathrm{CI}=0.79$ to $1.06, p=0.277)$ in a fixed-effect model $\left(\mathrm{I}^{2}=0 \%\right.$, Cochran's $\mathrm{Q}=1.511$ ) (Figure 2) that was not statistically significant.

Secondary analysis. The mean difference in procedure time, length of hospital stay, number of retrieved lymph nodes, metastasis in no. 10 and no. $11 \mathrm{~d}$ nodes, as well as the OR of perioperative mortality and postoperative complications comparing splenectomy to spleen preservation were investigated as a secondary analysis (Table II).

Operative time and hospital stay. All selected studies not reporting operative time and hospital stay, with the exclusion of that by $\mathrm{Yu}$ et al. (16), were pooled in the analysis. No significant difference in operative time between the two groups was found in a fixed-effect model [mean difference (MD) $=0.13$ $\min , 95 \% \mathrm{CI}=0.01-0.28 \mathrm{~min}, p=0.079]$. Similarly, two studies reporting data on the length of hospital stay $(16,18)$ and the estimated effect size indicated no significant difference between the groups $(\mathrm{MD}=0.06 ; 95 \% \mathrm{CI}=0.36-0.48, p=0.783)$.

Significant heterogeneity was found among the included studies $\left(\mathrm{I}^{2}=77.8 \%, p<0.05\right)$, and a random-effect analysis model was used.

Number of retrieved lymph nodes. Only two studies $(16,18)$ with a total of 712 patients presented data for retrieved lymph nodes and the estimated effect size indicated the number of lymph nodes retrieved was higher in the splenectomy group $(\mathrm{MD}=0.18,95 \% \mathrm{CI}=0.03$ to $0.32, p<0.05)$. Furthermore, no significant differences with regard to the histological metastasis rate in no. 10 and no. 11d nodes were highlighted between the two groups $(15,16,18)$ (Table II).

Perioperative mortality. Two studies reported data regarding in-hospital mortality on a total of 689 patients $(15,18)$. Overall mortality rate was $1.4 \%(5 / 344)$, ranging from 0.4 $4.4 \%$ in the splenectomy group, and $1.4 \%(5 / 345)$, ranging from $0.8-3.1 \%$ in the group with spleen preservation. The pooled analysis showed no statistically significant differences in perioperative mortality between the two groups $(\mathrm{OR}=1.06,95 \% \mathrm{CI}=0.29-3.86, p=0.925)$ in a fixedeffect model $\left(\mathrm{I}^{2}=0 \%, p<0.001\right)$.

Postoperative complications. All studies reporting overall morbidity highlighted statistically differences in favor of the group with spleen preservation, with a pooled analysis resulting in $(\mathrm{OR}=2.11,95 \% \mathrm{CI}=1.44-3.09, p<0.001)$ in a fixed-effect model (I2=0\%, $p=0.79)$.

Furthermore, an independent meta-analysis for surgical site infections and pulmonary complications was performed; no significant differences between splenectomy and spleenpreservation groups was highlighted. Interestingly, an independent meta-analysis showed that splenectomy was more likely than spleen preservation to result in intraperitoneal complications $(\mathrm{OR}=2.10,95 \% \mathrm{CI}=1.15-3.83$, $p<0.05)$ in a fixed effect model $(\mathrm{I} 2=0 \%, p=0.731)$.

Quality assessment. Two included studied $(15,18)$ were scored as being of high methodological quality and the other two $(16,17)$ of moderate quality according to QUIPS tool (28) (Table III). 


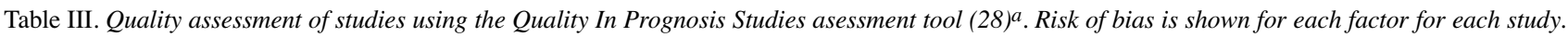

\begin{tabular}{lcccccc}
\hline Study & $\begin{array}{c}\text { Study } \\
\text { participation }\end{array}$ & $\begin{array}{c}\text { Study } \\
\text { attrition }\end{array}$ & $\begin{array}{c}\text { Prognostic factor } \\
\text { measurement }\end{array}$ & $\begin{array}{c}\text { Outcome } \\
\text { measurement }\end{array}$ & $\begin{array}{c}\text { Study } \\
\text { confounding }\end{array}$ & $\begin{array}{c}\text { Statistical analysis } \\
\text { and reporting }\end{array}$ \\
\hline Sano et al. (18) & Low & Low & Moderate & Low & Low & Low \\
Yu et al. $(16)$ & Moderate & High & Moderate & Low & Moderate & Low \\
Csendes et al. $(15)$ & Low & Moderate & Low & Low & Moderate & Moderate \\
Toge et al. $(17)$ & High & Moderate & Moderate & Moderate & Moderate & High \\
\hline
\end{tabular}

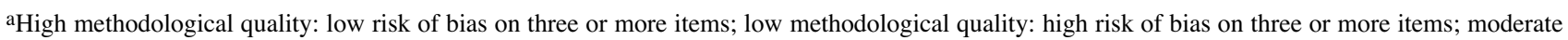
methodological quality: all other values.

\section{Discussion}

Results from our meta-analysis show that there appears to be no statistically significant prognostic difference in terms of OS between patients treated with splenectomy versus those with spleen preservation for curable proximal gastric carcinoma. Furthermore, the pooled operative morbidity outcomes favored the group which underwent spleenpreserving surgery, with mean odds of developing postoperative complications in the splenectomy-treated group being twice as high.

Initially, even if in the absence of any supporting evidence, the Japanese Gastric Cancer Treatment Guidelines suggested splenectomy for achieving clearance of nodal station 10 for potentially curable T2-T4 tumors invading the greater curvature of the upper stomach (14). Four years later, the Japanese Gastric Cancer Association revised their gastric cancer treatment guidelines, recommending splenectomy only for those with T2-T4 tumors either directly invading the spleen or located in the greater curvature of the upper stomach (12).

Several attempts have been made to investigate whether splenectomy is essential from an oncological point of view, but research comparing splenectomy with spleen-preserving surgery for non-metastatic proximal gastric cancer shows diverging outcomes. Wanebo et al. identified an adverse effect of splenectomy on prognosis (21), whereas Kanayama et al. supported there being a survival advantage (32). Moreover, increased postoperative morbidity and mortality were indicated in several retrospective studies $(21,33,34)$. Similarly, they failed to show any survival advantage for splenectomy over spleen preservation $(35,36)$. These results, however, may be unreliable since the studies were affected by the limitations of their retrospective approach. Four prospective RCTs were conducted to evaluate splenectomy in total gastrectomy. The trial by Yu et al. on 207 patients in a single institution showed a slightly but not significantly better overall 5-year survival associated with splenectomy rather than spleen preservation (54.8\% vs. 48.8\%) (16).
Csendes et al. prospectively compared the early and late results of total gastrectomy versus total gastrectomy plus splenectomy on a total of 187 patients with proximal gastric carcinoma (15). Survival analysis highlighted a 42\% 5-year survival rate for those treated with splenectomy as opposed to $36 \%$ for the spleen-preservation group, without statistical significance. A better prognosis was also suggested for the splenectomy-treated group of another small-scale Japanese RCT (79 patients) reported in 1985 (17). Furthermore, a meta-analysis by Yang et al. concluded that there was no statistically significant survival benefits associated with splenectomy when compared with spleen-preserving surgery and routinely performing splenectomy should not be recommended (37). However, it should be pointed out that the sample size of these RCTs was limited, and a welldesigned RCT is necessary to explore the effectiveness of splenectomy, especially for proximal and whole gastric cancer. Recently the largest multi-institutional RCT on a total of 505 patients with gastric cancer was published, showing statistically significant non-inferiority of spleen preservation to splenectomy in 5-year survival rates $(76.4 \% \mathrm{vs} .75 .1 \%$, $p=0.025)(12)$. This prompted us to prepare a systematic review of the literature with meta-analysis of updated available data to provide a more robust answer regarding the oncological effectiveness and safety of splenectomy for the treatment of proximal gastric cancer.

The current meta-analysis involved four studies with 978 patients (489 treated with splenectomy): two of them (15, 18) were of high methodological quality and the other two $(16,17)$ of moderate quality according to the QUIPS tool (28). The oncological effectiveness, in terms of OS, was the primary outcome of this study. R0 resection with D2 lymphadenectomy is currently recommended as the standard of surgical treatment with curative intent by the Japanese, Korean, Italian, German and British national guidelines, by the European Society for Medical Oncology (ESMO) guidelines, as well as the joint ESMO-European Society of Surgical Oncology (ESSO)-European Society of Radiotherapy and Oncology guidelines (38). However, the 
main target of gastric cancer surgery is to preserve postoperative functionality and quality of life, without reducing long-term outcomes by means of a tailored approach (39). To this address, splenectomy in total gastrectomy for proximal resectable gastric cancer is suggested in the case of splenic or pancreatic invasion to achieve R0 resection. Splenectomy should be also performed in the absence of direct infiltration, aiming at complete lymphadenectomy at the splenic hilum (no. 10 station) since $8-20 \%$ of cases of proximal gastric cancer metastasize to the lymph nodes in this area and complete dissection can represent a surgical challenge without splenectomy $(18,40$ 42). According to our results, splenectomy did not affect patient survival compared to spleen-preserving surgery for proximal gastric cancer. Furthermore, even though splenectomy resulted in a higher number of retrieved lymph nodes, no significant differences as regards the histological metastasis rate in no. 10 and no. $11 \mathrm{~d}$ nodes were highlighted between the two groups. There is no evidence to support that splenectomy improves the survival rate of patients with metastasis to the lymph nodes at the splenic hilum or along the splenic artery $(16,37,43,44)$. Since the frequency of splenic hilar lymph node metastasis is associated with tumor stage, tumor location and nodal status, it could effectively be postulated that proximal gastric cancer not involving the greater curvature has very low possibility of no. 10 lymph node metastasis, and that when it does metastasize to no. 10 nodes, disease is already extensive and the addition of splenectomy to total gastrectomy would be ineffective ( 35 , 45-48). Additionally, long-term T-cell suppression in patients with gastric cancer after total gastrectomy with splenectomy may have a detrimental effect on immune surveillance, worsening survival outcomes (49).

With regard to the safety of splenectomy, operative time, hospital stay and postoperative mortality were equivalent between the two groups. On the other hand, a significant increase in postoperative complications were registered for the splenectomy group. The increased incidence of intraperitoneal infections after splenectomy, hypothetically due to the reduction of immunomodulation splenic activity (33) is of concern. Previous studies have reported higher morbidity rates, especially infectious complications, in patients undergoing splenectomy than those who did not $(15,50,52)$. Splenectomy has also been recognized as an independent risk factor influencing postoperative complications (21, 33, 53, 54). Recent European clinical trials of gastrectomy showed that splenectomy associated with extended lymph node dissection may even be harmful because of increased morbidity associated with the procedure $(19,20)$. Overall, our pooled outcomes on post-procedure complications confirmed these data. The spleen is an important component of the reticuloendothelial system and accounts for $25 \%$ of the total lymphoid tissue, contributing to blood cell monitoring and immune activities (55). Moreover, it is involved in protection from infectious agents by producing opsonins, as well as polyreactive antibodies (44). On this basis, it can be theorized that common complications after splenectomy such as sepsis, abdominal abscess, pneumonia and wound infection, could be caused by a loss of immunological functions following spleen removal (56).

Our study was affected by some limitations. First of all, the number of included RCTs is very low and two of the included studies were only of moderate methodological quality. Additionally, it would be of immense interest to evaluate the prognostic significance of lymph node metastasis at the splenic hilum and along the distal splenic artery for these two groups. Unfortunately, only in the study by $\mathrm{Yu}$ et al. (16) was this detailed information reported. Lastly, it would have been interesting to investigate the oncologic role of splenectomy for gastric cancer located at and limited to the greater curvature, since these tumors may metastasize only to no. 10 nodes, which can be cured by splenectomy $(47,57,58)$. In this regard, only a recent retrospective review of 108 patients with advanced proximal gastric cancer involving the greater curvature showed that splenectomy increases postoperative complication rate without clearly improving survival outcomes (59).

\section{Conclusion}

In total gastrectomy for proximal gastric cancer, splenectomy should not be recommended as it increases operative morbidity without improving survival when compared to spleen preservation. Furthermore, our results may help in planning the updated versions of Gastric Cancer Treatment Guidelines. This meta-analysis, however, points to the urgent need for high quality, well-designed, large-scale, clinical trials with short- as well as long-term evaluation comparing splenectomy with spleen-preserving procedures, in a controlled randomized manner, helping future research and establishing an evidence-based approach to gastric cancer treatment.

\section{Funding}

The Authors have no funds to disclose.

\section{Conflicts of Interest}

The Authors report no conflicts of interest in regard to this study and they alone are responsible for the content and writing of the article.

\section{Ethical Standards}

This study did not require the ethical approval and informed consent since all analyses were based on the previous published data. 


\section{References}

1 Fock KM: Review article: the epidemiology and prevention of gastric cancer. Aliment Pharmacol Ther 40: 250-260, 2014.

2 Marrelli D, Polom K, de Manzoni G, Morgagni P, Baiocchi GL and Roviello F: Multimodal treatment of gastric cancer in the West: Where are we going? World J Gastroenterol 21: 79547969, 2015.

3 Verdecchia A, Corazziari I, Gatta G, Lisi D, Faivre J, Forman D and EUROCARE Working Group: Explaining gastric cancer survival differences among European countries. Int J cancer 109: 737-741, 2004.

4 Dassen AE, Lemmens VEPP, van de Poll-Franse L V, Creemers GJ, Brenninkmeijer SJ, Lips DJ, Vd Wurff AAM, Bosscha K and Coebergh JWW: Trends in incidence, treatment and survival of gastric adenocarcinoma between 1990 and 2007: a populationbased study in the Netherlands. Eur J Cancer 46: 1101-1110, 2010.

5 Wu H, Rusiecki JA, Zhu K, Potter J and Devesa SS: Stomach carcinoma incidence patterns in the United States by histologic type and anatomic site. Cancer Epidemiol Biomarkers Prev 18: 1945-1952, 2009.

6 Kaneko S and Yoshimura T: Time trend analysis of gastric cancer incidence in Japan by histological types, 1975-1989. Br J Cancer 84: 400-405, 2001.

7 Henson DE, Dittus C, Younes M, Nguyen H and AlboresSaavedra J: Differential trends in the intestinal and diffuse types of gastric carcinoma in the United States, 1973-2000: increase in the signet ring cell type. Arch Pathol Lab Med 128: 765-770, 2004.

8 Marrelli D, Pedrazzani C, Morgagni P, de Manzoni G, Pacelli F, Coniglio A, Marchet A, Saragoni L, Giacopuzzi S, Roviello F and Italian Research Group for Gastric Cancer: Changing clinical and pathological features of gastric cancer over time. $\mathrm{Br}$ J Surg 98: 1273-1283, 2011.

9 Marrelli D, De Stefano A, de Manzoni G, Morgagni P, Di Leo A and Roviello F: Prediction of recurrence after radical surgery for gastric cancer: a scoring system obtained from a prospective multicenter study. Ann Surg 241: 247-255, 2005.

10 Kattan MW, Karpeh MS, Mazumdar M and Brennan MF: Postoperative nomogram for disease-specific survival after an R0 resection for gastric carcinoma. J Clin Oncol 21: 3647-3650, 2003.

11 Han D-S, Suh Y-S, Kong S-H, Lee H-J, Choi Y, Aikou S, Sano T, Park B-J, Kim W-H and Yang H-K: Nomogram predicting long-term survival after $\mathrm{d} 2$ gastrectomy for gastric cancer. J Clin Oncol 30: 3834-3840, 2012.

12 Kodera Y and Sano T: Japanese Gastric Cancer Treatment Guidelines 2014 (ver. 4). Gastric Cancer 20: 1-19, 2017.

13 Marano L, Polom K, Patriti A, Roviello G, Falco G, Stracqualursi A, De Luca R, Petrioli R, Martinotti M, Generali D, Marrelli D, Di Martino N and Roviello F: Surgical management of advanced gastric cancer: An evolving issue. Eur J Surg Oncol 42: 18-27, 2016.

14 Japanese Gastric Cancer Association: Japanese Gastric Cancer Treatment Guidelines 2010 (ver. 3). Gastric Cancer 14: 113-123, 2011.

15 Csendes A, Burdiles P, Rojas J, Braghetto I, Diaz JC and Maluenda F: A prospective randomized study comparing D2 total gastrectomy versus D2 total gastrectomy plus splenectomy in 187 patients with gastric carcinoma. Surgery 131: 401-407, 2002.

$16 \mathrm{Yu}$ W, Choi GS and Chung HY: Randomized clinical trial of splenectomy versus splenic preservation in patients with proximal gastric cancer. Br J Surg 93: 559-563, 2006.

17 Toge T, Kameda A, Kuroi K, Seto Y, Yamada H and Hattori T: The role of the spleen in immunosuppression and the effects of splenectomy on prognosis in gastric cancer patients. Nihon Geka Gakkai Zasshi 86: 1120-1123, 1985.

18 Sano T, Sasako M, Mizusawa J, Yamamoto S, Katai H, Yoshikawa T, Nashimoto A, Ito S, Kaji M, Imamura H, Fukushima N and Fujitani K: Randomized controlled trial to evaluate splenectomy in total gastrectomy for proximal gastric carcinoma. Ann Surg 265: 277-283, 2017.

19 Cuschieri A, Fayers P, Fielding J, Craven J, Bancewicz J, Joypaul V and Cook P: Postoperative morbidity and mortality after D1 and D2 resections for gastric cancer: preliminary results of the MRC randomised controlled surgical trial. The Surgical Cooperative Group. Lancet (London, England) 347: 995-999, 1996.

20 Bonenkamp JJ, Songun I, Hermans J, Sasako M, Welvaart K, Plukker JT, van Elk P, Obertop H, Gouma DJ and Taat CW: Randomised comparison of morbidity after D1 and D2 dissection for gastric cancer in 996 Dutch patients. Lancet (London, England) 345: 745-748, 1995.

21 Wanebo HJ, Kennedy BJ, Winchester DP, Stewart AK and Fremgen AM: Role of splenectomy in gastric cancer surgery: Adverse effect of elective splenectomy on longterm survival. J Am Coll Surg 185: 177-184, 1997.

22 Schmid A, Thybusch A, Kremer B and Henne-Bruns D: Differential effects of radical D2-lymphadenectomy and splenectomy in surgically treated gastric cancer patients. Hepatogastroenterology 47: 579-585, 2000.

23 Bonenkamp JJ, Hermans J, Sasako M, van de Velde CJ, Welvaart K, Songun I, Meyer S, Plukker JT, Van Elk P, Obertop H, Gouma DJ, van Lanschot JJ, Taat CW, de Graaf PW, von Meyenfeldt MF, Tilanus H and Dutch Gastric Cancer Group: Extended lymph-node dissection for gastric cancer. N Engl J Med 340: 908-914, 1999.

24 Fatouros M, Roukos DH, Lorenz M, Arampatzis I, Hottentrott $\mathrm{C}$, Encke A and Kappas AM: Impact of spleen preservation in patients with gastric cancer. Anticancer Res 25: 3023-3030, 2005.

25 Moher D, Shamseer L, Clarke M, Ghersi D, Liberati A, Petticrew M, Shekelle P and Stewart LA: Preferred reporting items for systematic review and meta-analysis protocols (PRISMA-P) 2015 statement. Syst Rev 4: 1, 2015.

26 Higgins JPT GS (ed): Cochrane Handbook for Systematic Reviews of Interventions Version 5.1.0 [updated March 2011]. Cochrane Collab, 2011. http://handbook-5-1.cochrane.org/ [Last accessed April 17 2018].

27 Richardson WS, Wilson MC, Nishikawa J and Hayward RS: The well-built clinical question: a key to evidence-based decisions. ACP J Club 123: A12-3, 1995.

28 Hayden JA, Côté P and Bombardier C: Evaluation of the quality of prognosis studies in systematic reviews. Ann Intern Med 144: 427-437, 2006.

29 Tierney JF, Stewart LA, Ghersi D, Burdett S and Sydes MR: Practical methods for incorporating summary time-to-event data into meta-analysis. Trials 8: 16, 2007. 
30 Sano T, Yamamoto S, Sasako M and Japan Clinical Oncology Group Study LCOG 0110-MF: Randomized controlled trial to evaluate splenectomy in total gastrectomy for proximal gastric carcinoma: Japan Clinical Oncology Group study JCOG 0110MF. Jpn J Clin Oncol 32: 363-364, 2002.

31 Sasako M, Sano T, Yamamoto S, Kurokawa Y, Nashimoto A, Kurita A, Hiratsuka M, Tsujinaka T, Kinoshita T, Arai K, Yamamura Y, Okajima K and Japan Clinical Oncology Group: D2 lymphadenectomy alone or with para-aortic nodal dissection for gastric cancer. N Engl J Med 359: 453-462, 2008.

32 Kanayama H, Hamazoe R, Osaki Y, Shimizu N, Maeta M and Koga S: Immunosuppressive factor from the spleen in gastric cancer patients. Cancer 56: 1963-1966, 1985.

33 Griffith JP, Sue-Ling HM, Martin I, Dixon MF, McMahon MJ, Axon AT and Johnston D: Preservation of the spleen improves survival after radical surgery for gastric cancer. Gut 36: 684690, 1995.

34 Wang F, Chang YC, Chen TH, Hsu J Te, Kuo CJ, Lin CJ, Chen JS, Chiang KC, Yeh T Sen, Hwang TL and Jan YY: Prognostic significance of splenectomy for patients with gastric adenocarcinoma undergoing total gastrectomy: A retrospective cohort study. Int J Surg 12: 557-565, 2014.

35 Nashimoto A, Yabusaki $\mathrm{H}$ and Matsuki A: The significance of splenectomy for advanced proximal gastric cancer. Int J Surg Oncol 2012: 301530, 2012.

36 Otsuji E, Yamaguchi T, Sawai K, Ohara M and Takahashi T: End results of simultaneous splenectomy in patients undergoing total gastrectomy for gastric carcinoma. Surgery 120: 40-44, 1996.

37 Yang K, Chen XZ, Hu JK, Zhang B, Chen ZX and Chen JP: Effectiveness and safety of splenectomy for gastric carcinoma: A meta-analysis. World J Gastroenterol 15: 5352-5359, 2009.

38 Marano L, Marrelli D and Roviello F: Focus on research: Nodal dissection for gastric cancer - A dilemma worthy of King Solomon! Eur J Surg Oncol 42: 1623-1624, 2016.

39 Ohdaira H, Nimura H, Mitsumori N, Takahashi N, Kashiwagi H and Yanaga $\mathrm{K}$ : Validity of modified gastrectomy combined with sentinel node navigation surgery for early gastric cancer. Gastric Cancer 10: 117-122, 2007.

40 Mönig SP, Collet PH, Baldus SE, Schmackpfeffer K, Schröder W, Thiele J, Dienes HP and Hölscher AH: Splenectomy in proximal gastric cancer: frequency of lymph node metastasis to the splenic hilus. J Surg Oncol 76: 89-92, 2001.

41 Maruyama K, Gunvén P, Okabayashi K, Sasako M and Kinoshita T: Lymph node metastases of gastric cancer. General pattern in 1931 patients. Ann Surg 210: 596-602, 1989.

42 Okajima K and Isozaki $\mathrm{H}$ : Splenectomy for treatment of gastric cancer: Japanese experience. World J Surg 19: 537-540, 1995.

43 Kodera Y, Yamamura Y, Shimizu Y, Torii A, Hirai T, Yasui K, Morimoto T, Kato T and Kito T: Lack of benefit of combined pancreaticosplenectomy in D2 resection for proximal-third gastric carcinoma. World J Surg 21: 622-628.

44 Zhang CH, Zhan WH, He YL, Chen CQ, Huang MJ and Cai SR: Spleen preservation in radical surgery for gastric cardia cancer. Ann Surg Oncol 14: 1312-1319, 2007.

45 Shin SH, Jung H, Choi SH, An JY, Choi MG, Noh JH, Sohn TS, Bae JM and Kim S: Clinical significance of splenic hilar lymph node metastasis in proximal gastric cancer. Ann Surg Oncol 16: 1304-1309, 2009.
46 Zhu G, Sun Z, Wang Z, Xu Y, Huang B, Xu Y, Zhu Z and Xu H: Splenic hilar lymph node metastasis independently predicts poor survival for patients with gastric cancers in the upper and/or the middle third of the stomach. J Surg Oncol 105: 786-792, 2012.

47 Sasada S, Ninomiya M, Nishizaki M, Harano M, Ojima Y, Matsukawa H, Aoki H, Shiozaki S, Ohno S and Takakura N: Frequency of lymph node metastasis to the splenic hilus and effect of splenectomy in proximal gastric cancer. Anticancer Res 29: 3347-3451, 2009.

48 Sun Z, Wang Z, Zhu G, Huang B, Li K, Xu Y, Li D and Xu H: Advanced Gastric Cancer with early cancer macroscopic appearance: Is it worthy of D2 lymphadenectomy? Ann Surg Oncol 17: 1278-1290, 2010.

49 Okuno K, Tanaka A, Shigeoka H, Hirai N, Kawai I and Kitano Y: Suppression of T-cell function in gastric cancer patients after total gastrectomy with splenectomy: implications of splenic autotransplantation. Gastric Cancer 2: 20-25, 1999.

50 Brady MS, Rogatko A, Dent LL and Shiu MH: Effect of splenectomy on morbidity and survival following curative gastrectomy for carcinoma. Arch Surg 126: 359-364, 1991.

51 Weitz J, Jaques DP, Brennan M and Karpeh M: Association of splenectomy with postoperative complications in patients with proximal gastric and gastroesophageal junction cancer. Ann Surg Oncol 11: 682-689, 2004.

52 Ducoulombier S, Golfier F, Colomban O, Benayoun D, Bolze PA, Tod M and You B: Modeling CA-125 during neoadjuvant chemotherapy for predicting optimal cytoreduction and relapse risk in ovarian cancer. Anticancer Res 37: 6879-6886, 2017.

53 Kwon SJ: Prognostic impact of splenectomy on gastric cancer: results of the Korean Gastric Cancer Study Group. World J Surg 21: 837-844, 1997.

54 Brady MS, Rogatko A, Dent LL and Shiu MH: Effect of splenectomy on morbidity and survival following curative gastrectomy for carcinoma. Arch Surg 126: 359-364, 1991.

55 Ellison EC and Fabri PJ: Complications of splenectomy. Etiology, prevention, and management. Surg Clin North Am 63: 1313-1330, 1983.

56 Adachi Y, Kamakura T, Mori M, Maehara Y and Sugimachi K: Role of lymph node dissection and splenectomy in node-positive gastric carcinoma. Surgery 116: 837-841, 1994.

57 Aoyagi K, Kouhuji K, Miyagi M, Imaizumi T, Kizaki J and Shirouzu K: Prognosis of metastatic splenic hilum lymph node in patients with gastric cancer after total gastrectomy and splenectomy. World J Hepatol 2: 81-86, 2010.

58 Kosuga T, Ichikawa D, Okamoto K, Komatsu S, Shiozaki A, Fujiwara H and Otsuji E: Survival benefits from splenic hilar lymph node dissection by splenectomy in gastric cancer patients: relative comparison of the benefits in subgroups of patients. Gastric Cancer 14: 172-127, 2011.

59 Ohkura Y, Haruta S, Shindoh J, Tanaka T, Ueno M and Udagawa $\mathrm{H}$ : Efficacy of prophylactic splenectomy for proximal advanced gastric cancer invading greater curvature. World J Surg Oncol 15: 106, 2017.

Received March 20, 2018

Revised April 15, 2018

Accepted April 17, 2018 